\title{
A Model Problem for an Open Robotics Controller
}

Scott A. Hissam

Mark Klein

July 2004

Predictable Assembly from Certifiable

Components Initiative

Unlimited distribution subject to the copyright.

Technical Note

CMU/SEI-2004-TN-030 
This work is sponsored by the U.S. Department of Defense.

The Software Engineering Institute is a federally funded research and development center sponsored by the U.S. Department of Defense.

Copyright 2004 Carnegie Mellon University.

NO WARRANTY

THIS CARNEGIE MELLON UNIVERSITY AND SOFTWARE ENGINEERING INSTITUTE MATERIAL IS FURNISHED ON AN "AS-IS" BASIS. CARNEGIE MELLON UNIVERSITY MAKES NO WARRANTIES OF ANY KIND, EITHER EXPRESSED OR IMPLIED, AS TO ANY MATTER INCLUDING, BUT NOT LIMITED TO, WARRANTY OF FITNESS FOR PURPOSE OR MERCHANTABILITY, EXCLUSIVITY, OR RESULTS OBTAINED FROM USE OF THE MATERIAL. CARNEGIE MELLON UNIVERSITY DOES NOT MAKE ANY WARRANTY OF ANY KIND WITH RESPECT TO FREEDOM FROM PATENT, TRADEMARK, OR COPYRIGHT INFRINGEMENT.

Use of any trademarks in this report is not intended in any way to infringe on the rights of the trademark holder.

Internal use. Permission to reproduce this document and to prepare derivative works from this document for internal use is granted, provided the copyright and "No Warranty" statements are included with all reproductions and derivative works.

External use. Requests for permission to reproduce this document or prepare derivative works of this document for external and commercial use should be addressed to the SEI Licensing Agent.

This work was created in the performance of Federal Government Contract Number F19628-00-C-0003 with Carnegie Mellon University for the operation of the Software Engineering Institute, a federally funded research and development center. The Government of the United States has a royalty-free government-purpose license to use, duplicate, or disclose the work, in whole or in part and in any manner, and to have or permit others to do so, for government purposes pursuant to the copyright license under the clause at 252.227-7013.

For information about purchasing paper copies of SEI reports, please visit the publications portion of our Web site (http://www.sei.cmu.edu/publications/pubweb.html). 


\section{Contents}

Acknowledgements......................................................................................... vii

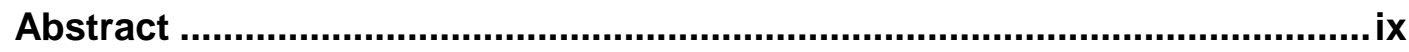

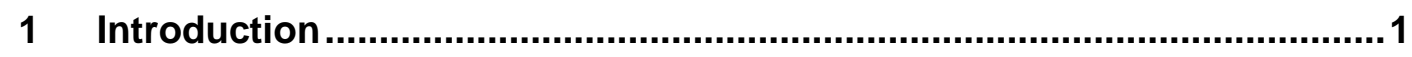

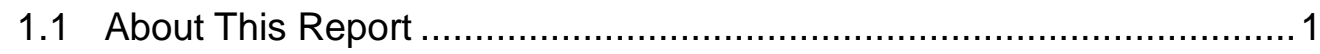

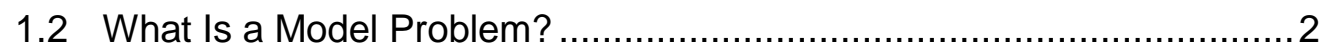

1.3 About the Open Robotics Controller (ORC) ……............................

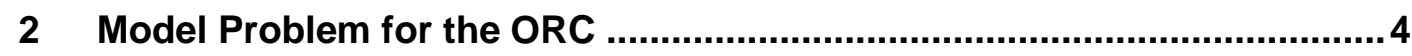

2.1 Main Computer Task Descriptions ..............................................

2.2 Significant States for the Model Problem ..........................................

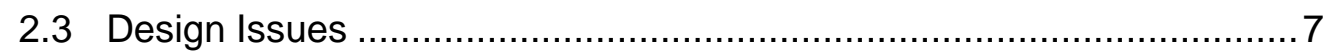

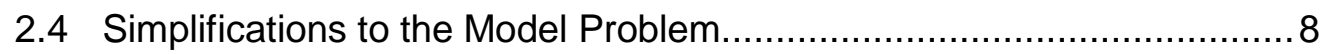

2.5 Summary Task Performance Specifications........................................ 8

3 Future Work

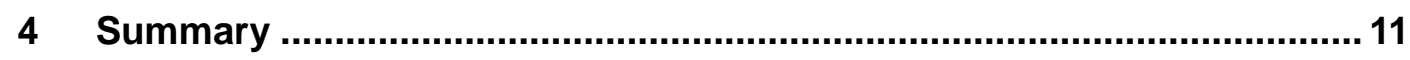

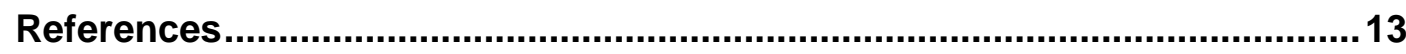




\section{List of Figures}

Figure 1: High-Level Structure of a Model Problem......................................... 2

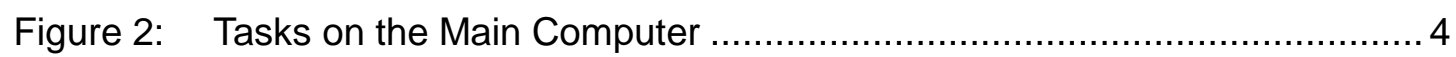




\section{List of Tables}

Table 1: $\quad$ Behavior of Tasks $A_{i}, B_{i}$, and $C$ in Different States ........................... 7

Table 2: $\quad$ Performance Description of Model Problem Tasks .............................. 9 


\section{Acknowledgements}

The authors would like to gratefully acknowledge the assistance of Anders Wall for his patience and thoughtfulness in answering all the questions raised regarding the abstractions created for the Open Robotics Controller and in working through the details so that we had the model problem correct. 


\section{Abstract}

This report describes the model problem created to support the continued enhancement and development of the prediction-enabled component technology (PECT) reasoning frameworks for an industrial trial in the domain of industrial robotics. The model problem described in this report is an abstract representation of the parallel tasking and component configuration typically seen in a successful industrial robotics controller. Although motivated by the domain of industrial robotics, the model problem is applicable to other domains typified by embedded control systems consisting of both periodic and stochastic behavior and using fixed-priority scheduling with real-time performance characteristics. 


\section{Introduction}

The Predictable Assembly from Certifiable Components (PACC) Initiative at the Carnegie Mellon ${ }^{\circledR}$ Software Engineering Institute (SEI) investigates the technology and methods for reliably predicting the runtime behavior of assemblies of components from their certifiable properties. ${ }^{1}$ The approach to achieving assemblies that are predictable by construction is based on the development of prediction-enabled component technologies (PECTs) [Wallnau 03].

A PECT comprises a construction framework and one or more reasoning frameworks. The construction framework is associated with a specific component technology that provides the essential means to construct any one assembly. A reasoning framework is based on a theory and used to analyze the behavior of an assembly with respect to specific runtime properties (for example, latency, safety, or liveness).

Two previous applications of the PECT approach have been documented [Hissam 01, Hissam 02]. The first was a proof of concept for the PECT approach using a component technology developed initially to support the U.S. Environmental Protection Agency's (EPA's) Department of Water Quality. The second was an industrial trial in substation automation systems (within the domain of power generation and transmission) conducted in partnership with the ABB Corporate Research Center (ABB/CRC).

In both prior applications, the reasoning frameworks constructed to achieve predictable assembly were illustrated using the development of a model problem.

\subsection{About This Report}

This paper describes the model problem created to support the continued enhancement and development of the PECT reasoning frameworks for a third industrial trial. That trial is in the domain of industrial robotics and is being conducted in partnership with the ABB/CRC; ABB Automation Technology Products, Robotics $;{ }^{2}$ and the Department of Computer Science and Engineering, Mälardalen University.

${ }^{\circledR}$ Carnegie Mellon is registered in the U.S. Patent and Trademark Office by Carnegie Mellon University.

1 For more information on the PACC Initiative, go to http://www.sei.cmu.edu/pacc/pacc_init.html.

2 For more information on ABB robotics, go to http://www.abb.com/robotics. 
The model problem described in this report is an abstract representation of the parallel tasking and component configuration typically seen in ABB's S4 generation robotics controller.

\subsection{What Is a Model Problem?}

Essentially, a model problem is a reduction of a design issue to its simplest form from which one or more model solutions can be investigated. A model solution is a demonstration of a design, implementation, or example that addresses the issue posed by the model problem (see Figure 1). The model problem approach is an adaptation of model problems discussed by Wallnau, Hissam, and Seacord [Wallnau 01].

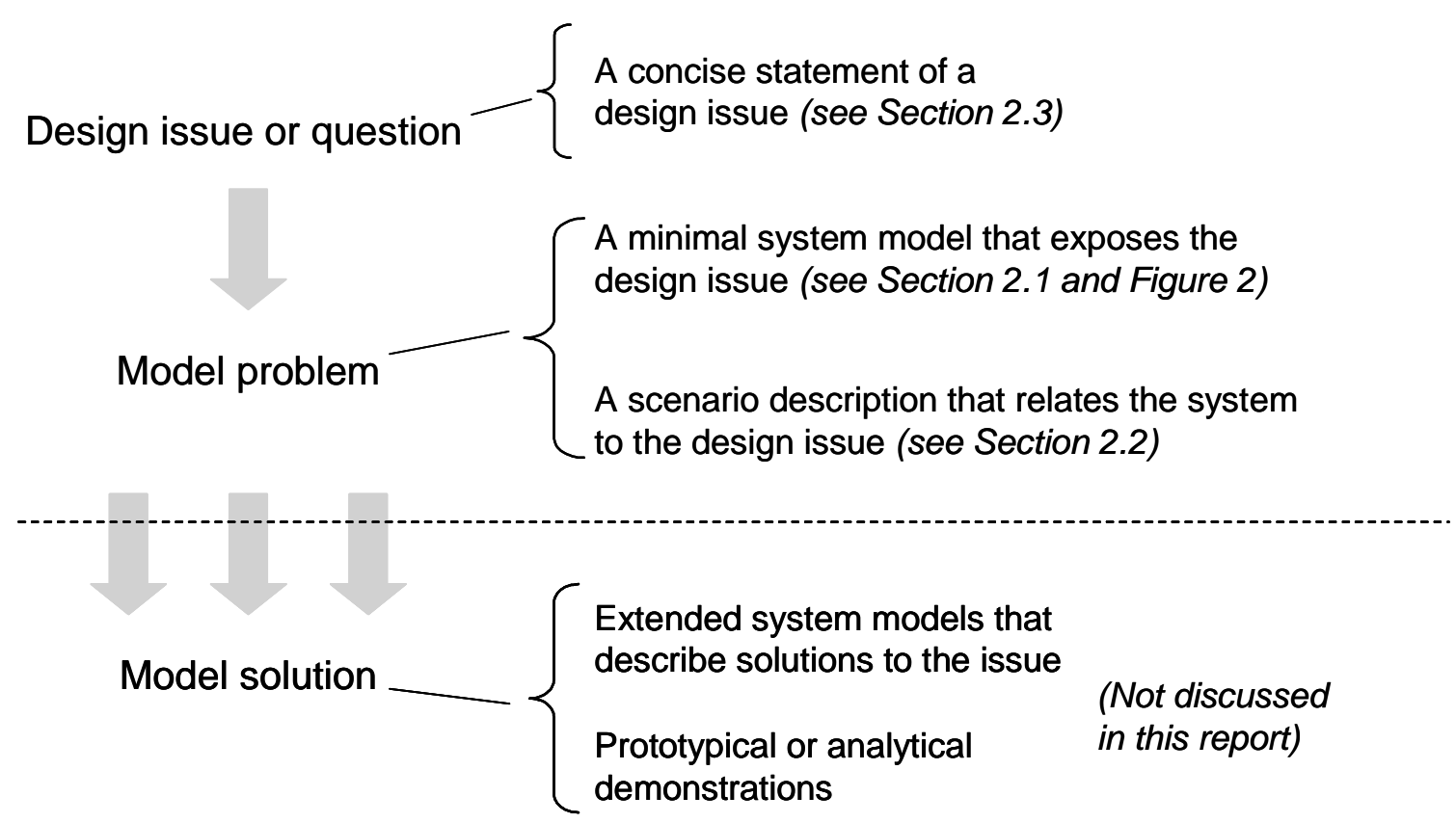

Figure 1: High-Level Structure of a Model Problem

In this report, we set up the model problem and describe the design issues, the minimal system model, and the states of the model problem significant to the design issues. Any specific model solutions to address those issues are the focus of future work and beyond the scope of this report.

\subsection{About the Open Robotics Controller (ORC)}

ABB Robotics is contemplating its future robotics platform, currently dubbed the Open Robotics Controller (ORC). A critical design feature of this new platform is the ability to customize the controller with user-added extensions. These extensions, made by ABB or other companies, are augmentations to the core controller platform. Although such capability enables $\mathrm{ABB}$ to give continued strategic business value to its customers, such extensions to 
the platform could introduce technical problems in controlling or predicting the impact any one extension (once incorporated) may have on the robotics platform.

The ORC's design is understandably focused on two quality attributes: performance and safety. It is not difficult to foresee the potential poor performance or instability introduced through a user-added extension. By analogy, common off-the-shelf operating systems (OSs) permit third-party device drivers that, when flawed, cause unexpected or unwanted behavior potentially impacting quality attributes of the system as a whole. ABB Robotics wants to be able to permit the incorporation of third-party extensions to the ORC and predict the impact the extensions will have on the core controller platform's quality attributes.

The performance aspects of the ORC motivate this model problem. ABB wants to predict the invasiveness one or more extensions will have on the core controller platform a priori. In this way, ABB will be able to do two things: (1) know what the new performance characteristics of the ORC will be once one or more extensions are incorporated and (2) determine whether those characteristics still fall within the required performance envelope. Ultimately, such a capability will enable the creation of component specifications that vendors can adhere to, thereby ensuring that extensions will work in context without breaking the core controller platform. 


\section{Model Problem for the ORC}

The ORC can be thought of as a number of parallel, intercommunicating threads of execution within the core controller platform. That platform typically consists of a single Intel Celeron processor running VxWorks and is referred to as the main computer. The main computer communicates with one or more computers called axis computers.

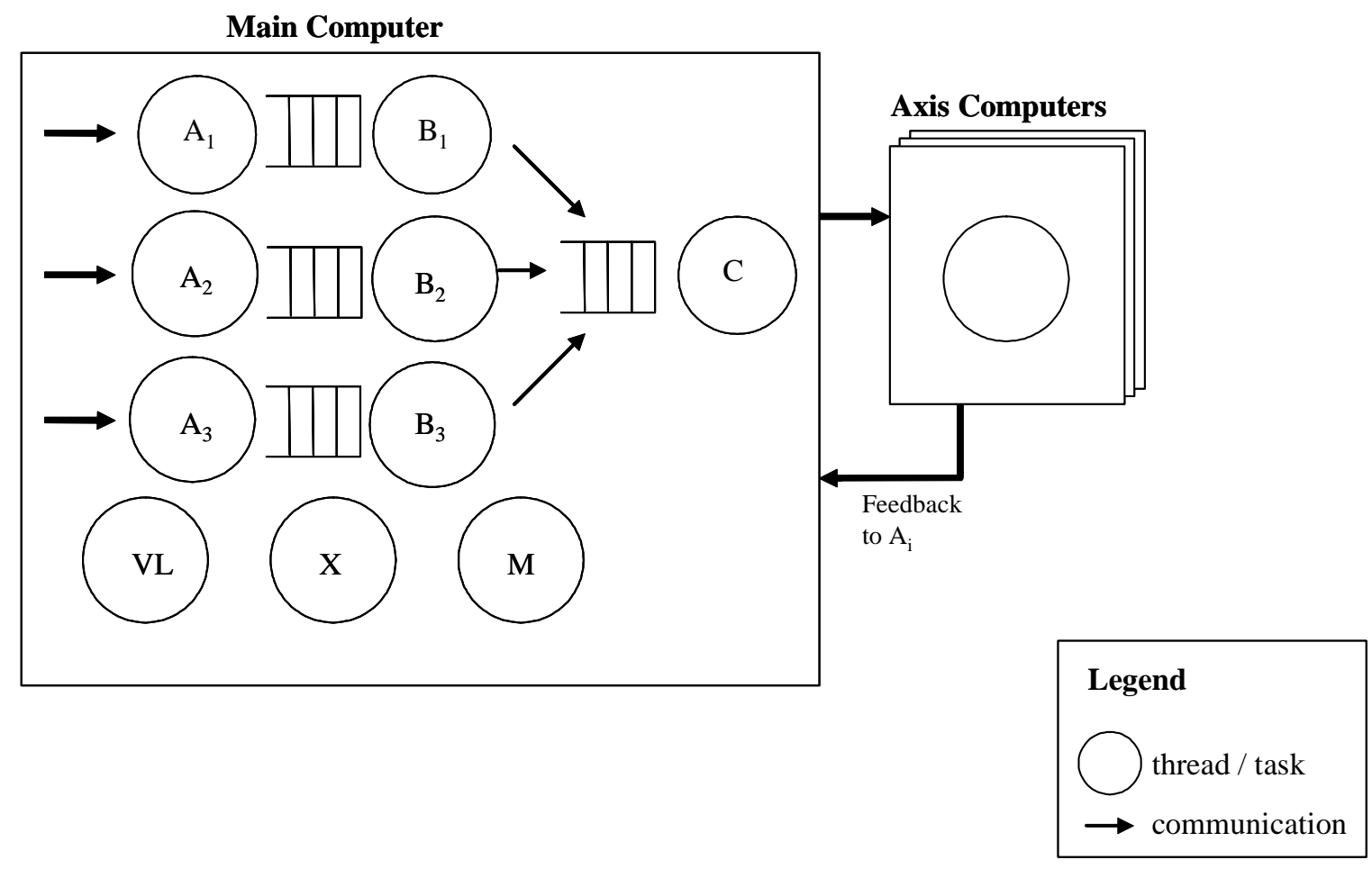

\section{Figure 2: Tasks on the Main Computer}

The model problem focuses on the interaction between tasks in the main computer. That computer is responsible for running programs (written in the high-level Rapid robot programming language) that generate work orders. ${ }^{3}$ Those orders are decomposed into subwork orders that ultimately result in communicating microcoordinates to an axis computer that contains the device drivers responsible for the actual movement of the robotic arm (or arms).

3 A Rapid program consists of one or more commands to a robot (much like setting a goal, such as "move here at this speed") that are broken down into one or more subwork orders (for instance, steps to achieving that goal). 
The threads that execute on the main computer are a mix of periodic ${ }^{4}$ and aperiodic ${ }^{5}$ tasks, performing a mix of synchronous and asynchronous interthread communication. Much of the asynchronous type of communication germane to this report is conducted through first in, first out (FIFO) queues. Extensions, at this time, are envisioned to be separate threads of control. For the purpose of this model problem, only a subset of threads housed on the main computer are deemed critical. Those threads of control are shown in Figure 2 and described in the remainder of this section.

\subsection{Main Computer Task Descriptions}

There are six main tasks: $A_{i}, B_{i}, C, X, M$, and VL, each described below.

$\mathbf{A}_{\mathbf{i}}$ tasks. Three $\mathrm{A}_{\mathrm{i}}$ tasks — where $i$ stands for 1, 2, or 3 - carry out planning activities: primarily, they receive work orders and create plans. Each plan produced by Task $A_{i}$ results in a sequence of subwork orders that are asynchronously passed to Task $\mathrm{B}_{\mathrm{i}}$. Typically, the queue size for subwork orders is set to 30 in the core controller platform. When Task $A_{i}$ produces subwork orders and attempts to place one into a full queue, Task $A_{i}$ becomes blocked until Task $\mathrm{B}_{\mathrm{i}}$ removes an item from that queue, thereby making room for the new subwork order. This system behavior is considered normal.

The axis computer sends feedback to Task $A_{i}$ indirectly - that is, it delivers feedback first synchronously to Task $\mathrm{C}$ (described below) in the main computer, and then Task $\mathrm{C}$ "publishes" it to those tasks subscribed to that feedback (Task $\mathrm{A}_{i}$ being one of them). Because this feedback informs the planning process; planning can't be done entirely in advance.

The arrival rates of work orders to Task $A_{i}$ vary ranging from $10 \mathrm{~Hz}$ (i.e., one every $100 \mathrm{~ms}$ ) to $15 \mathrm{~Hz}^{6}$ (i.e., one every $66.7 \mathrm{~ms}$ ). For this model problem, we assume that the arrivals are describable via Exponential(75) (i.e., exponential random distribution with a mean of $75 \mathrm{~ms}$ ).

The execution time of Task $\mathrm{A}_{\mathrm{i}}$ - the time needed to decompose a work order into a sequence of subwork orders-is also highly variable. For this model problem, we assume that Task $\mathrm{A}_{\mathrm{i}}$ 's execution times are describable using Exponential(9).

Currently, Tasks $\mathrm{A}_{1}-\mathrm{A}_{3}$ execute at a relatively low priority because they have a relatively long execution time (in the aggregate). That is, although the execution time to decompose one work order is fairly short [describable using Exponential(9)], given the relatively high interarrival interval of the work orders to Tasks $\mathrm{A}_{1},-\mathrm{A}_{3}$, a sudden large number of work

4 A periodic task is one that implements the response to a periodic event (one of a sequence of events having constant interarrival intervals) and thus becomes ready to execute at fixed intervals [Klein 93].

5 An aperiodic task is one that implements the response to an aperiodic event (one of a sequence of events not having constant interarrival intervals).

6 This is the maximum frequency; in practice, the frequency is less. 
orders could cause those tasks to monopolize the central processing unit (CPU), if the tasks are given a high priority.

The only timing requirement for the $A_{i}$ tasks is to ensure that the queue between Task $A_{i}$ and its respective Task $B_{i}$ does not become empty during the processing of a work order (see Section 2.2).

$\mathbf{B}_{\mathbf{i}}$ tasks. The $\mathrm{B}_{\mathrm{i}}$ tasks-where $i$ stands for 1, 2, or 3-also participate in planning. A queue between Task $A_{i}$ and Task $B_{i}$ contains the subwork orders placed in that queue by Task $A_{i}$. The $\mathrm{B}_{\mathrm{i}}$ tasks have an execution time of between 1 and $2 \mathrm{~ms}$ and execute periodically with a period of $24 \mathrm{~ms}$. Once, each $24 \mathrm{~ms}$ period, Task $B_{i}$ will remove one subwork order from this queue, generate six individual microcoordinates, and place them in Task C's queue. Task $\mathrm{B}_{\mathrm{i}}$ 's execution time includes the time it takes to transform a subwork order to six microcoordinates and place them in Task C's queue.

The $\mathrm{B}_{\mathrm{i}}$ tasks execute at a much higher priority than the $\mathrm{A}_{\mathrm{i}}$ tasks do. The $\mathrm{B}_{\mathrm{i}}$ tasks must complete their work before the end of their period.

Task C. The single Task $\mathrm{C}$ executes with a period of $4 \mathrm{~ms}$. Task $\mathrm{C}$ receives microcoordinates (i.e., robot movement command) from one or more $\mathrm{B}_{\mathrm{i}}$ tasks and sends them regularly to the various axis computers controlling the various robot arms-in this case, to three different axis computers controlling three different robot arms. (Each Task $A_{i}-B_{i}$ pair is associated with its own robot arm.) Task $\mathrm{C}$ will read only one microcoordinate from the queue during its $4 \mathrm{~ms}$ period. The execution time of Task $\mathrm{C}$ is 0.5 to $1 \mathrm{~ms}$, and its priority is very high. The task's deadline is the end of its period.

The queue between Task $B_{i}$ and Task $C$ must never become empty while the robot is turned on. If it does, the robot's controller will consider it to be an unsafe condition and abnormally halt the robot.

Task X. Task X represents high-priority OS functions that occur rarely and execute for a short amount of time.

M tasks. The M tasks are medium-priority tasks that represent the third-party controller extensions. M tasks are important because, on one hand, they have timing requirements of their own that must be satisfied; on the other hand, they can delay the execution of Task $A_{i}$ and therefore interfere with that task's ability to keep at least one work order in the queue. For this model problem, two types of $\mathrm{M}$ tasks are considered: one with stochastic characteristics and one with deterministic characteristics. The characteristics of two M tasks are listed in Table 2 below. We assume that the deterministic $M$ task $\left(M_{1}\right)$ has a deadline at the end of its period, while the stochastic $\mathrm{M}$ task $\left(\mathrm{M}_{2}\right)$ has a soft deadline. 
Task VL. Task VL represents miscellaneous work that is carried out at the lowest priority in the system. We assume that this work arrives periodically with a period of 5 seconds and executes for $250 \mathrm{~ms}$ (at a utilization of .02).

\subsection{Significant States for the Model Problem}

Although the ORC has a significant number of states in which it operates, representing all of them is not necessary for the model problem. Instead, two operating states need to be considered: in motion or not in motion. Further, the only transition is one that takes the model problem from its initial not in motion state to an in motion state. ${ }^{7}$

That transition is triggered after Task $A_{i}$ has received the first work order and successfully placed the subwork orders in the queue between Task $A_{i}$ and Task $B_{i}$. Tasks $A_{i}, B_{i}$, and $C$ have different behaviors when the model problem is in a not in motion state versus an in motion state. Those behaviors are characterized in Table $1 .^{8}$

\begin{tabular}{||l|l|l|}
\hline \hline TASK & BEHAVIOR WHILE NOT IN MOTION & BEHAVIOR WHILE IN MOTION \\
\hline \hline $\mathrm{A}_{\mathrm{i}}$ & Waiting for the first work order & $\begin{array}{l}\text { Consuming work orders and producing } \\
\text { subwork orders }\end{array}$ \\
\hline $\mathrm{B}_{\mathrm{i}}$ & $\begin{array}{l}\text { Only producing "stand still" } \\
\text { microcoordinates }\end{array}$ & $\begin{array}{l}\text { Consuming subwork orders and producing } \\
\text { "movement" microcoordinates }\end{array}$ \\
\hline $\mathrm{C}$ & Consuming microcoordinates & Consuming microcoordinates \\
\hline
\end{tabular}

Table 1: Behavior of Tasks $A_{i}, B_{i}$, and $C$ in Different States

Once in motion, we assume (for the purpose of analysis) a steady state condition never to return to a not in motion state.

\subsection{Design Issues}

Given the system context, there are two distinct design issues of interest:

1. the addition of platform extensions to the core controller platform

2. the potential for FIFO queue underflow conditions

With respect to the first issue, one of the main problems facing the ORC is how to predict the consequences of extensions. Extensions are intended to be augmentations to the core controller platform and are created by ABB or third-party "extension" developers (such as

7 Returning to a not in motion state was deemed unnecessary because the design issues concerned behavior in the steady state (i.e., in motion).

8 n.b.: Because the $\mathrm{M}_{1}, \mathrm{M}_{2}, \mathrm{X}$, and VL tasks behave in the same manner for the model problem regardless of the state, they are not included.

9 Task $\mathrm{A}_{\mathrm{i}}$ is considered not in motion until the first work order is received—at which point it is in motion. The remaining tasks aren't considered in motion until after the initial subwork orders are produced and queued. 
end users). For those reasons, it is critical to know what timing consequences can be introduced into the core controller platform as a result of "plugging in" an extension. A goal for this model problem, then, is to identify one or more model solutions that permit the specification of performance parameters for extensions so those extensions will not cause performance problems. In particular, extensions are envisioned for M tasks.

The second issue concerns the probability of a queue underflow exception, mainly between $A_{i}$ and $B_{i}$ tasks. Since $A_{i}$ tasks run at a priority relatively lower than $M_{i}$ tasks, the introduction of one or more extensions could conceivably starve Task $A_{i}$ enough that it doesn't receive enough execution time to sufficiently feed the queue before Task $\mathrm{B}_{\mathrm{i}}$-thus resulting in an underflow exception. In practice, prior to the concept of introducing platform extensions to the controller, this particular queue has been known to empty in very rare situations. Therefore, an additional goal for the model problem is to identify one or more model solutions that would significantly decrease or absolutely eliminate the possibility of an underflow exception occurring for this queue.

\subsection{Simplifications to the Model Problem}

Based on an understanding of the execution behavior and context of the ORC, we made a few simplifications (of the abstractions presented in the prior section).

First, Task VL was deemed uninteresting because it operates at a priority below Task $A_{i}$ and, therefore, cannot impact Task $A_{i}$ or any other task in the system. If the starvation of Task VL becomes a design issue later, the task could be reintroduced into the model problem.

Although in the actual core controller platform, the $\mathrm{A}_{\mathrm{i}}$ tasks cannot process all the work orders without considering feedback from the axis computer, the feedback was removed as an explicit interaction from the model problem. However, the time to process the feedback was factored into the execution time for the $\mathrm{A}_{\mathrm{i}}$ tasks.

Lastly, to keep the model problem as simple as possible, we decided to only allow one $A_{i} / B_{i}$ task pair (i.e., $i=1$ ). Therefore, the model problem will assume that the ORC being modeled has only one robotic arm.

However, design issues might be identified later that will dictate the reintroduction of the components we chose to remove.

\subsection{Summary Task Performance Specifications}

Table 2 summarizes the types of tasks in the model problem and their relevant performance characteristics. 
Periodic tasks are characterized as having constant arrivals. Aperiodic tasks have random arrivals following an exponential distribution. Traffic intensity $(\rho)$ is the quotient of expected execution time $(E[S])$ over the expected interarrival interval $(E[T])$.

\begin{tabular}{|c|c|c|c|c|c|}
\hline TASK & PRIORITY & ARRIVALS & $\begin{array}{l}\text { EXECUTION } \\
\text { TIME }\end{array}$ & $\begin{array}{c}\rho= \\
E[S] / E[T]\end{array}$ & COMMENTS \\
\hline$A_{1}$ & Low & $\begin{array}{l}\text { Exponential } \\
75 \mathrm{~ms}\end{array}$ & $\begin{array}{l}\text { Exponential } \\
9 \mathrm{~ms}\end{array}$ & .12 & $\begin{array}{l}\text { Planner: takes work orders } \\
\text { and produces subwork orders; } \\
\text { could result from a joystick or } \\
\text { a Rapid program. Must feed } \\
\text { queue so that it never under } \\
\text { runs }\end{array}$ \\
\hline $\mathrm{B}_{1}$ & High & $\begin{array}{l}\text { Constant } \\
24 \mathrm{~ms}\end{array}$ & $\begin{array}{l}\text { Uniform } \\
1-2 \mathrm{~ms}\end{array}$ & .06 & Works on subwork orders \\
\hline C & Very high & $\begin{array}{l}\text { Constant } 4 \\
\text { ms }\end{array}$ & $\begin{array}{l}\text { Constant } \\
0.5-1 \mathrm{~ms}\end{array}$ & .19 & $\begin{array}{l}\text { Sends command to axis } \\
\text { computer }\end{array}$ \\
\hline $\mathrm{M}_{1}$ & Medium & $\begin{array}{l}\text { Constant } \\
100 \mathrm{~ms}\end{array}$ & $\begin{array}{l}\text { Constant } \\
10 \mathrm{~ms}\end{array}$ & .10 & $\begin{array}{l}\text { Might be involved with } \\
\text { operating specific hardware. } \\
\text { Has a deadline at the end of } \\
\text { its period }\end{array}$ \\
\hline$M_{2}$ & Medium & $\begin{array}{l}\text { Exponential } \\
100 \mathrm{~ms}\end{array}$ & $\begin{array}{l}\text { Uniform } \\
15-25 \mathrm{~ms}\end{array}$ & .20 & $\begin{array}{l}\text { Has a soft deadline of } 750 \mathrm{~ms} \\
\text { after its arrival; it must } \\
\text { complete before this deadline } \\
\text { with a probability of } .9 \text {. }\end{array}$ \\
\hline$\overline{\mathrm{VL}}$ & Very low & $\begin{array}{l}\text { Constant } \\
250 \mathrm{~ms}\end{array}$ & $\begin{array}{l}\text { Constant } \\
5 \mathrm{~ms}\end{array}$ & .02 & \\
\hline$x$ & High & $\begin{array}{l}\text { Exponential } \\
500 \mathrm{~ms}\end{array}$ & $\begin{array}{l}\text { Constant } \\
1 \mathrm{~ms}\end{array}$ & .002 & $\begin{array}{l}\text { Represents rare OS services } \\
\text { with fairly constant execution } \\
\text { times }\end{array}$ \\
\hline
\end{tabular}

Table 2: $\quad$ Performance Description of Model Problem Tasks 


\section{Future Work}

To address the two primary design issues discussed in this paper, we intend to apply the Sporadic Server design pattern [Sprunt 89, Gonzalez Harbour 91]. This pattern offers a possible solution for limiting the invasiveness of the introduced extensions on the remainder of the core controller platform. Further, we intend to use that pattern to guarantee a sufficient number of CPU cycles to Task $A_{i}$ such that the task is guaranteed to supply the subwork order queue at a sufficient rate.

We intend to use this model problem to further the development of the performance reasoning framework for the PECT currently supporting our third industrial trial. In addition to the design issues, this work will include the following research tasks:

- Generalize our performance reasoning framework to include the use of real-time queuing theory and heavy traffic queuing theory.

- Develop a common approach to measuring task execution traces in the model problem that is sufficient and compatible with the ORC and supporting trace queries.

- Specify the construction and analysis invariants that must be satisfied by components and assemblies in order for the reasoning framework to produce valid results.

This performance reasoning framework will help predict the behavior of assemblies when the following conditions are true:

- Embedded controllers are confined to a single CPU.

- Each periodic event is handled by one task or one sequence of tasks.

- Each aperiodic event is handled by one task or one sequence of tasks.

- Aperiodic arrivals are describable by a random, exponential distribution.

- Scheduling between the tasks in the controller is managed by a fixed-priority scheduler.

- Each task is describable as having a hard or soft deadline and has a fixed execution time.

The above characteristics apply to the model problem described in this report. The problem also extends to other domains with similar characteristics. 


\section{Summary}

The model problem approach has been used by the PACC Initiative in two prior application domains to illustrate predictable assembly through the development of PECTs. This report describes the model problem in the domain of industrial robotics (e.g., the ORC) and serves as a sufficient abstraction of a real-world system (see Section 2.1) with real-world design issues (see Section 2.3). Such an abstraction can result in potential solutions for the ORC. Although situated in the domain of industrial robotics, this model problem can also be extended to other domains and real-world situations with characteristics similar to those described in this report. 


\section{References}

URLs are valid as of the publication date of this document.

[Gonzalez Harbour 91] Gonzalez Harbour, M. \& Sha, L. An Application-Level Implementation of the Sporadic Server (CMU/SEI-91-TR-026, ADA242129). Pittsburgh, PA: Software Engineering Institute, Carnegie Mellon University, 1991.

http://www.sei.cmu.edu/publications/documents/91.reports 191.tr.026.html

[Hissam 01]

[Hissam 02]

Hissam, S.; Moreno, G.; Stafford, J.; \& Wallnau, K. Packaging Predictable Assembly with Prediction-Enabled Component Technology (CMU/SEI-2001-TR-024, ADA399793). Pittsburgh, PA: Software Engineering Institute, Carnegie Mellon University, 2001. http://www.sei.cmu.edu/publications/documents/01.reports /01tr024.html

Hissam, S.; Hudak, J.; Ivers, J.; Klein, M.; Larsson, M.; Moreno, G.; Northrop, L.; Plakosh, D.; Stafford, J.; Wallnau, K.; \& Wood, W. Predictable Assembly of Substation Automation Systems: An Experiment Report, Second Edition (CMU/SEI-2002-TR-031, ADA418441). Pittsburgh, PA: Software Engineering Institute, Carnegie Mellon University, 2002. http://www.sei.cmu.edu /publications/documents/02.reports/02tr031.html

[Klein 93]

Klein, M.; Ralya, T.; Pollak, B.; Obenza, R.; and Gonzalez Harbour, M. A Practitioner's Handbook for Real-Time Analysis: Guide to Rate Monotonic Analysis for Real-Time Systems. Boston, MA:

Kluwer Academic Publishers, 1993.

http://www.sei.cmu.edu/publications/books

/other-books/rma.hndbk.html 
[Sprunt 89]

[Wallnau 01]

[Wallnau 03]
Sprunt, B.; Sha, L.; \& Lehoczky, J. Scheduling Sporadic and Aperiodic Events in a Hard Real-Time System (CMU/SEI-89-TR11, ADA211344). Pittsburgh, PA: Software Engineering Institute, Carnegie Mellon University, 1989. http://www.sei.cmu.edu /publications/documents/89.reports/89.tr.011.html

Wallnau, K.; Hissam, S.; \& Seacord, R. Building Systems from Commercial Components. Boston, MA: Addison-Wesley, 2001 (ISBN 0201700646). http://www.sei.cmu.edu/publications/books /engineering/building-systems.html

Wallnau, K. Volume III: A Technology for Predictable Assembly from Certifiable Components (CMU/SEI-2003-TR-009, ADA413574). Pittsburgh, PA: Software Engineering Institute, Carnegie Mellon University, 2003. http://www.sei.cmu.edu /publications/documents/03.reports/03tr009.html 


\begin{tabular}{|c|c|c|c|c|}
\hline \multicolumn{3}{|c|}{ REPORT DOCUMENTATION PAGE } & \multicolumn{2}{|c|}{$\begin{array}{l}\text { Form Approved } \\
\text { OMB No. 0704-0188 }\end{array}$} \\
\hline \multicolumn{5}{|c|}{ 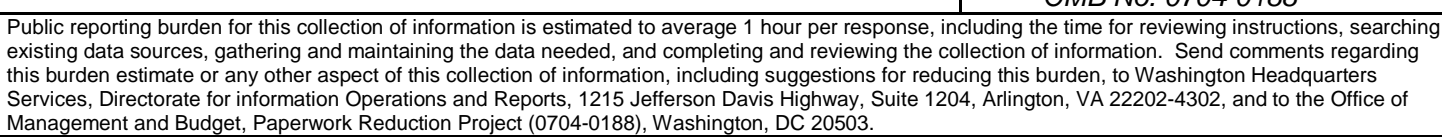 } \\
\hline (Leave Blank) & \multicolumn{2}{|c|}{$\begin{array}{l}\text { tion Project (0704-0188), Washington, DC 20503. } \\
\text { 2. REPORT DATE } \\
\text { July } 2004\end{array}$} & \multicolumn{2}{|c|}{$\begin{array}{l}\text { 3. REPORT TYPE AND DATES COVERED } \\
\text { Final }\end{array}$} \\
\hline \multicolumn{3}{|c|}{$\begin{array}{l}\text { mILEANDSUBTILE } \\
\text { A Model Problem for an Open Robotics Controller }\end{array}$} & \multicolumn{2}{|c|}{$\begin{array}{ll}\text { 5. } & \text { FUNDING NUMBERS } \\
& \text { F19628-00-C-0003 }\end{array}$} \\
\hline \multicolumn{5}{|c|}{$\begin{array}{ll}\text { 6. } & \text { AUTHOR(S) } \\
\text { Scott A. Hissam, Mark Klein }\end{array}$} \\
\hline \multicolumn{3}{|c|}{$\begin{array}{l}\text { PERFOPMNG ORGANZATIONNAME(S) AND ADDRESS(ES) } \\
\text { Software Engineering Institute } \\
\text { Carnegie Mellon University } \\
\text { Pittsburgh, PA } 15213\end{array}$} & \multicolumn{2}{|c|}{$\begin{array}{ll}\text { 8. } & \text { PERFORMNG ORGANZATION } \\
\text { REPORT NUMBER } \\
\text { CMU/SEI-2004-TN-030 }\end{array}$} \\
\hline \multicolumn{3}{|c|}{$\begin{array}{l}\text { 9. SPONSORING/MONTORING AGENCY NAME(S) AND ADDRESS(ES) } \\
\text { HQ ESC/XPK } \\
5 \text { Eglin Street } \\
\text { Hanscom AFB, MA 01731-2116 } \\
\end{array}$} & \multicolumn{2}{|c|}{$\begin{array}{l}\text { 10. SPONSORING/MONTORING AGENCY } \\
\text { REPORT NUMBER }\end{array}$} \\
\hline \multicolumn{5}{|c|}{ 11. SUPPLEMENTARY NOTES } \\
\hline \multicolumn{3}{|c|}{$\begin{array}{l}\text { 12A DISTRIBUTIONAVALABIUTYSTATEMENT } \\
\text { Unclassified/Unlimited, DTIC, NTIS }\end{array}$} & \multicolumn{2}{|c|}{ 12B DISTRIBUTIONCODE } \\
\hline \multicolumn{5}{|c|}{$\begin{array}{l}\text { 13. ABSTRACT (MAXIMUM200 WORDS) } \\
\text { This report describes the model problem created to support the continued enhancement and development of } \\
\text { the prediction-enabled component technology (PECT) reasoning frameworks for an industrial trial in the } \\
\text { domain of industrial robotics. The model problem described in this report is an abstract representation of the } \\
\text { parallel tasking and component configuration typically seen in a successful industrial robotics controller. } \\
\text { Although motivated by the domain of industrial robotics, the model problem is applicable to other domains } \\
\text { typified by embedded control systems consisting of both periodic and stochastic behavior and using fixed- } \\
\text { priority scheduling with real-time performance characteristics. }\end{array}$} \\
\hline \multicolumn{3}{|c|}{$\begin{array}{l}\text { SUBJECT TERMS } \\
\text { model problem; sporadic server; robotics; performance; performance } \\
\text { theory; PACC; PECT; component technology; software engineering }\end{array}$} & \multicolumn{2}{|c|}{$\begin{array}{l}\text { 15. NUMBER OF PAGES } \\
26\end{array}$} \\
\hline \multicolumn{5}{|l|}{ 16. PRICECODE } \\
\hline $\begin{array}{l}\text { 17. SECURTY CLASSIFCATION } \\
\text { OF REPORT } \\
\text { Unclassified }\end{array}$ & $\begin{array}{l}\text { 18. SECURTYCLASSIFCATION OF } \\
\text { THISPAGE } \\
\text { Unclassified }\end{array}$ & $\begin{array}{l}\text { 19. SECURTYYCA } \\
\text { ABSTRACT } \\
\text { Unclassifie }\end{array}$ & SIFCAMIONOF & $\begin{array}{l}\text { 20. LMTATION OF ABSTRACT } \\
\text { UL }\end{array}$ \\
\hline
\end{tabular}

